Research

\title{
Impact of postgraduate study on healthcare professionals' academic and clinical practice
}

Samantha Holloway ${ }^{1}$, Ann Taylor ${ }^{1}$, Michal Tombs ${ }^{1}$

${ }^{1}$ School of Medicine, Centre for Medical Education, College of Biomedical and Life Sciences, Cardiff University, Cardiff, UK

Correspondence to:

Samantha Holloway (Holloways11 @cf.ac.uk) 


\begin{abstract}
Aims/Background Existing literature in the healthcare setting indicates that individuals enter higher education, particularly postgraduate programmes, to gain in-depth knowledge of a subject area with a view to improving their career opportunities. Evidence also suggests that, in addition to perceived career enhancement, individuals also report benefits such as personal growth and broadening of perspectives, which has helped their clinical practice. The aim of this study was to examine the impact of postgraduate study on healthcare professionals' academic practice and discuss the potential links to improvements in clinical practice.
\end{abstract}

Method This was a descriptive cross-sectional survey of a convenience sample of graduates from a range of postgraduate healthcare programmes at one UK university. A survey comprising 18 questions was designed to tap into perceptions of impact and was distributed to 962 graduates with a response rate of $9.81 \%(n=98)$.

Results The majority of respondents were doctors $(n=54,55.1 \%)$, women $(n=59,60.2 \%)$, based within the UK $(n=36,36.7 \%)$ and had completed their programme between 2014 and $2016(n=72)$. With regards to achievements in professional practice, findings suggest that participants felt more confident in relation to research and evaluating evidence. In relation to impact on clinical practice, improvements in multidisciplinary team working as well as increased confidence emerged as main themes.

Conclusions Findings support existing evidence in relation to the importance of postgraduate study being able to instil an increased sense of confidence in graduates' ability, which was particularly related to having a better understanding of speciality-related evidence and its application in clinical practice. This is something that previous studies do not seem to have reported and may reflect the multiprofessional nature of many of the postgraduate programmes provided.

Key words Academic skills, Clinical practice, Healthcare professionals, Master's programmes, Postgraduate education

Received: 18 June 2019; accepted after double-blind peer review: 16 March 2020

\title{
Introduction
}

A number of previous studies have examined the impact of Master's preparation (Whyte et al, 2000), postregistration degrees (Hardwick and Jordan, 2002) and higher education (Spencer, 2006) on healthcare professionals' practice. Existing evidence from the medical education field has also indicated that healthcare professionals can benefit from professional qualifications in teaching which in turn had an effect on clinical treatment and practice (Steinert, 2000; Gruppen et al, 2003).

\section{Impact of postgraduate nursing programmes}

Whyte et al (2000) undertook a 10-year follow-up study of graduates of a full-time Master's programme in nursing-related subjects at a university in Scotland. The results indicated that having a Master's degree was linked to more job opportunities and these graduates felt that their clinical practice had been enhanced. Themes emerged in relation to 'personal satisfaction' and 'achievement', particularly related to academic skills attainment. A distinct theme was also 'personal growth', linked to the notion of 'intellectual sharing', 'broadening of perspectives' and possessing advanced 'powers of reasoning'.

A subsequent study in 2002 by Hardwick and Jordan examined the impact of part-time postregistration degrees in nursing and midwifery (Bachelor's and Master's) on practice. Graduates 
$(n=58)$ were from a single institution in a university in South Wales and had graduated between 1994 and 1998. They were contacted by post and asked to provide feedback on topics such as motivational factors, perceptions of use of skills and changes in practice related to the programme, and also barriers to implementation of skills. The response rate was $74 \%(n=43)$ with the majority reporting that their graduate skills had been used in clinical practice $(n=33,77 \%)$, although specific examples of this were not provided.

A later qualitative study by Spencer (2006) examined the perceptions of nurses, midwives and health visitors in relation to the impact of higher education on their professional practice. Using a phenomenological approach the author interviewed 12 individuals who had undertaken an MSc in Professional Practice at a Higher Education Institution in the East Midlands. Using content analysis the author identified four themes: 'personal and professional motivation', 'workplace constraints', 'valuing hands-on nursing and client contact', and 'challenging/questioning practice'.

\section{Impact of medical education programmes}

In a 1-year post-completion survey, Steinert (2000) found that many faculty members had joined new educational committees, taken on new leadership roles in medical education, and developed new courses for students and residents. Similar results were reported by Gruppen et al (2003) at the University of Michigan.

A qualitative study by de Cossart et al (2012) to examine the progression of senior clinicians $(n=11)$ on a Master's programme found that within the first year of the programme participants had already reported substantial positive changes in their clinical teaching, taking on more teaching in the clinical setting. They felt that their teaching had become more efficient, less time consuming and more learner centred. They reported greater awareness of their own approach to teaching and their educational values, and their supervision and assessment of junior staff had become more rigorous. They also felt that the programme had far-reaching benefits for their clinical treatment and practice, becoming better at reflecting on their own practice and articulating their decisions. Participants who had come from the same institution provided mutual support to one another, which led to new ideas for educational projects that extend well beyond the course, increasing faculty collaboration.

The existing evidence points to a number of areas that postgraduate education has an impact on, the majority of the literature indicating that the benefits relate to aspects of personal development. There are also indications that higher education study can impact on clinical practice, but specific examples of this were difficult to identify in the current literature. Based on this gap, the School of Medicine at Cardiff University undertook a project to determine the impact of postgraduate study from a healthcare-related subject area on graduates' academic skills and clinical practice.

For the purposes of the project core academic skills were considered to be literature searching, planning and use of evidence as well as academic writing, critical analysis and referencing. Additional academic skills relate to personal and professional development and include areas such as reflection, enquiry and problem-solving.

\section{Methods}

\section{Background: setting for the project}

Within the School of Medicine, the Centre for Medical Education at Cardiff University offers a wide range of programmes including postgraduate certificates, postgraduate diplomas, Master's, standalone modules and continuing professional development for large numbers of professional learners. The majority of programmes are delivered on a part-time basis, either taught, blended or 
fully online, enabling students to work while they study. Students are recruited from over 90 countries, although the majority are based in the UK. Graduates represent a diverse range of healthcare backgrounds.

A descriptive cross-sectional survey was used in this project to investigate the impact of postgraduate studies on graduates' professional and clinical practice. Given the geographical disparity of potential participants, the survey method was suitable for a project of this nature. A link to a survey was distributed by individual programme teams via email to a total of 962 graduates from the programmes at the Centre for Medical Education. It is therefore acknowledged that the results from this project are specific to this setting rather than being more widely generalisable.

\section{Sample}

Potential respondents had to have graduated at least 12 months previously. An opportunity sampling method was used to ensure all graduates had the opportunity to participate. In total 10 programmes took part in the survey with a total of 98 graduates responding, which represents a response rate of $9.81 \%$. The majority of responses $(n=60)$ came from graduates of the diabetes $(n=22)$, dermatology $(n=19)$ and wound healing $(n=19)$ programmes. The majority of the respondents were doctors $(n=54,55.1 \%)$, women $(n=59,60.2 \%)$, based in the UK $(n=36,36.7 \%)$ and had completed their programme between 2014 and $2016(n=72)$. Most respondents self-funded their studies $(n=65,58 \%)$. Therefore, it should be borne in mind that the findings relate more to female postgraduates and those who are working within the medical profession specifically. In addition there was a bias in terms of geographical location with fewer overseas students being represented.

\section{Data collection}

There was no existing tool to examine the impact of postgraduate studies on academic skills and clinical practice, therefore a questionnaire was developed. To ensure items accurately assessed personal and professional development resulting from completing the postgraduate course, the authors consulted the literature (Steinert, 2000; Whyte et al, 2000; Hardwick and Jordan, 2002; Gruppen et al, 2003; Spencer, 2006) and combined the themes identified with questions from the Destination of Leavers from Higher Education survey (Higher Education Statistics Agency 2017). The Destination of Leavers from Higher Education survey is sent to UK and EU domiciled graduates only, 6 months after qualifying from higher education programmes. To enhance reliability and validity of the items, a draft of the questionnaire was circulated to the postgraduate review group to establish whether they felt the items assessed both personal and professional development.

The online survey was administered using the Bristol Online Surveys (Bristol University) software and comprised 18 questions in total. This included seven questions to determine demographic information, for example sex, name of the programme undertaken, time since graduation, professional background and country of work. The questionnaire also examined whether the qualification was needed for their current role. To establish acquisition of academic skills the survey included open and closed questions related to opportunities to publish, implementation of recommendations arising from dissertation projects in clinical practice, preparation for the workplace in relation to skills, knowledge, employability, adaptability, leadership and management, research or audit and lifelong learning (two open-ended questions and five closed questions). Other questions examined the impact of the programme in relation to intellectual stimulation, relevance and learning in the work context, ability to implement change and overall impact in the workplace (four closed questions). The majority of questions asked respondents to report their level of agreement on a fivepoint Likert scale ( $1=$ strongly agree to $5=$ strongly disagree).

The project did not require ethical approval as this was considered to be an educational evaluation project. However, permission to undertake the survey was granted by the postgraduate 
review group within the School of Medicine at Cardiff University. Data were handled according to the University's data handing and records management policies. No respondent identifiable information was used.

\section{Results}

Data for each programme were analysed to provide overall frequencies and descriptive statistics (number and percent).

In response to the question 'Was the qualification needed to get the role you are performing', approximately one-third of respondents reported that the qualification was not a formal requirement $(n=34,34.7 \%)$, and the same number reported that, while the qualification was not a formal requirement for the role they were undertaking, they felt it did give them an advantage $(n=34$, $34.7 \%)$. The remaining respondents reported that the qualification was a requirement of their role $(n=30,30.6 \%)$.

With regards to skills and knowledge acquisition, employability, adaptability, leadership and management, research or audit and lifelong learning the results showed the respondents agreed that they felt prepared across all the domains, with knowledge acquisition and lifelong learning being rated highly (strongly agree and agree domains) (Table 1).

\section{Table 1. Responses to the question 'Overall, how well has the programme of study you undertook prepared you for the workplace in relation to the following areas?'}

\begin{tabular}{|l|c|c|c|c|c|}
\hline & $\begin{array}{l}\text { Strongly } \\
\text { agree }\end{array}$ & Agree & $\begin{array}{l}\text { Neither agree } \\
\text { or disagree }\end{array}$ & Disagree & $\begin{array}{l}\text { Strongly } \\
\text { disagree }\end{array}$ \\
\hline Skills & $43(43.9 \%)$ & $40(40.8 \%)$ & $14(14.3 \%)$ & $1(1 \%)$ & 0 \\
\hline $\begin{array}{l}\text { Knowledge } \\
\text { acquisition }\end{array}$ & $59(60.2 \%)$ & $34(34.7 \%)$ & $4(4.1 \%)$ & $1(1 \%)$ & 0 \\
\hline Employability & $34(35.1 \%)$ & $42(43.3 \%)$ & $18(18.6 \%)$ & $2(2.1 \%)$ & $1(1 \%)$ \\
\hline Adaptability & $41(41.8 \%)$ & $41(41.8 \%$ & $15(15.3 \%)$ & $1(1 \%)$ & 0 \\
\hline $\begin{array}{l}\text { Leadership and } \\
\text { management }\end{array}$ & $29(29.6 \%)$ & $45(45.9 \%)$ & $20(20.4 \%)$ & $4(4.1 \%)$ & 0 \\
\hline $\begin{array}{l}\text { Research or } \\
\text { audit }\end{array}$ & $40(40.8 \%)$ & $45(45.9 \%)$ & $11(11.2 \%)$ & $2(2 \%)$ & 0 \\
\hline $\begin{array}{l}\text { Lifelong } \\
\text { learning }\end{array}$ & $57(58.2 \%)$ & $36(36.7 \%)$ & $4(4.1 \%)$ & $1(1 \%)$ & 0 \\
\hline
\end{tabular}

In relation to intellectual stimulation, relevance to work, application of learning, ability to make changes, and impact on the workplace, the results showed a stronger level of agreement across the five domains with relevance to work context and intellectual stimulation being rated higher (strongly agree and agree domains) (Table 2).

\begin{tabular}{|c|c|c|c|c|c|}
\hline & $\begin{array}{l}\text { Strongly } \\
\text { agree }\end{array}$ & Agree & $\begin{array}{l}\text { Neither agree } \\
\text { or disagree }\end{array}$ & Disagree & $\begin{array}{l}\text { Strongly } \\
\text { disagree }\end{array}$ \\
\hline $\begin{array}{l}\text { Intellectual } \\
\text { stimulation }\end{array}$ & $67(68.4 \%)$ & $27(27.6 \%)$ & $3(3.1 \%)$ & 0 & $1(1 \%)$ \\
\hline $\begin{array}{l}\text { Relevance to work } \\
\text { context or personal } \\
\text { and professional } \\
\text { development }\end{array}$ & $68(69.4 \%)$ & $29(29.6 \%)$ & $1(1 \%)$ & 0 & 0 \\
\hline
\end{tabular}




\begin{tabular}{|l|c|c|c|c|c|}
\hline $\begin{array}{l}\text { Application of } \\
\text { learning in } \\
\text { professional context }\end{array}$ & $60(61.2 \%)$ & $35(35.7 \%)$ & $3(3.1 \%)$ & 0 & 0 \\
\hline $\begin{array}{l}\text { Ability to make } \\
\text { changes in practice }\end{array}$ & $55(56.1 \%)$ & $38(38.8 \%)$ & $4(4.1 \%)$ & $1(1 \%)$ & 0 \\
\hline $\begin{array}{l}\text { Impact on the } \\
\text { workplace }\end{array}$ & $46(46.9 \%)$ & $38(38.8 \%)$ & $12(12.2 \%)$ & $2(2 \% 0$ & 0 \\
\hline
\end{tabular}

In recognition of the limitations of the self-report survey, open questions were designed to further drill into graduates' perceptions of the impact of their studies. Open questions asked about impact on professional practice, possible benefits gained from doing the dissertation, and a more general question related to what they have learned and gained from the course.

Participants were asked to provide an example of something they had achieved in their professional practice as a direct result of studying. The responses showed that graduates felt more confident overall, particularly in relation to research and evaluating evidence. More specifically, and in relation to impact on their clinical practice, respondents were asked to provide examples that demonstrated impact. Overall the main theme of multidisciplinary team working emerged along with an associated increase in confidence. The responses also reflected clinical impact in terms of improved approaches to clinical audit, care pathways, clinical protocols and departmental policies for management of specific diseases or conditions (Table 3). These findings reflect some of the principles of evidence-based practice, specifically basing clinical practice on evaluation of evidence as well as clinical expertise, which in this study is interpreted in terms of the increased confidence respondents reported.

\begin{tabular}{|l|}
\hline Table 3. Examples of impact on clinical practice \\
\hline Multidisciplinary team working and increased confidence as part of that team* \\
\hline Changes to way clinical audit is undertake \\
\hline Informed service delivery and service developments \\
\hline Encouraged enrolment on to PhD programme \\
\hline Staff training and teaching \\
\hline $\begin{array}{l}\text { Improved care pathways or clinical protocols and departmental policies for management of } \\
\text { conditions, for example diabetic foot disease or respiratory conditions }\end{array}$ \\
\hline Improved diagnostic strategies \\
\hline Improved level of independence \\
\hline New research projects, dedicated research time \\
\hline Focus on evidence-based medicine and practice \\
\hline *reported most frequently \\
\hline
\end{tabular}

In relation to the Master's dissertation, participants were asked to think about the impact of this on their professional practice. Of the total number of respondents $63.9 \%(n=62)$ had undertaken a dissertation. A number of themes emerged (Table 4). Many of the responses reflected those provided for the impact on clinical practice, with the addition of aspects of impact on academic development, for example, having opportunities to publish and presenting at conferences.

Table 4. Impact of Master's dissertation on graduates' professional practice

Encouraged enrolment on a $\mathrm{PhD}$ programme

Changed the way clinical audits are undertaken

Implementation of guidelines 


\begin{tabular}{|l|}
\hline Helped to inform departmental care pathways \\
\hline Encouraged joint research collaboration with a peer \\
\hline Opportunity to publish \\
\hline Developed 'just in time' training programme \\
\hline Created evidence-based respiratory strategy \\
\hline Changes in clinical practice, service delivery or policies \\
\hline Creation of an antibiotic protocol for febrile neutropenic patients \\
\hline Poster presentation at the European Society of Anaethesiology meeting \\
\hline
\end{tabular}

The most common themes in relation to what graduates had learned from, enjoyed about or applied as a result of undertaking the programme related to opportunities for networking with other healthcare professionals, building professional relationships and sharing views (Table 5). In relation to what skills the graduates had been able to apply in clinical practice the responses reflected the principles of evidence-based medicine/evidence-based practice.

Table 5. Most important thing the students learned or applied or enjoyed

\begin{tabular}{|c|c|}
\hline Enjoyed & $\begin{array}{l}\text { - Meeting and conversing with other practitioners* } \\
\text { - } \text { Building professional relationships with other students* } \\
\text { - Sharing views with others* } \\
\text { - Interacting with other students through groupwork or cases* } \\
\text { - } \text { Appreciate different clinical practices in other countries* } \\
\text { - Real case scenarios }\end{array}$ \\
\hline Applied & $\begin{array}{l}\text { - } \text { Reading research articles } \\
\text { - } \text { Seeking out valid research and evidence } \\
\text { - } \text { Critical appraisal } \\
\text { - } \text { Evidence based care } \\
\text { - } \text { How to undertake research } \\
\text { - } \text { Communicating better }\end{array}$ \\
\hline
\end{tabular}

"Most commonly reported

It is recognised that there are limitations to using a survey method for content analysis, as data may be limited and not as meaningful as they could have been had they been collected via an interview or a focus group. Further research could use other qualitative methods to enhance the validity of findings.

\section{Discussion}

Previous studies from nursing, midwifery and health visiting programmes were able to provide some insight into the positive impact of undertaking higher education on academic skills, but the research was based on uni-professional populations (Whyte et al, 2000; Hardwick and Jordan, 2002; Spencer, 2006). In relation to postgraduate medical education, evidence shows that healthcare professionals benefit greatly from undertaking a professional qualification in teaching (Steinert, 2000; Gruppen et al, 2003); however, these studies are quite dated and there was a lack of more recent data to support the role of higher education in healthcare.

The aim of this project was to determine the impact of postgraduate study on academic skills and clinical practice in graduates from a range of programmes of study. Overall the results showed 
that the majority of graduates reported an increased sense of confidence which is similar to previous studies (Steinert, 2000; Whyte et al, 2000; Gruppen et al, 2003). In addition the results of the current study identified achievements in relation to wider academic activities such as presenting at conferences, writing for publication, being invited to a board member of a specialist association, and creating academic training programmes. These findings correlate specifically with the studies by Gruppen et al (2003) and Steinert (2000) who reported a number of similar professional benefits following postgraduate study.

The additional information which the current study identified was that the increase in confidence appeared to be linked to a sense of having a better understanding of speciality-related evidence which they could apply in clinical practice, which was reflected in the free-text responses. There were also positive responses in terms of improved multidisciplinary teamwork being reported, which was linked closely to a sense of confidence. This is an aspect that previous studies do not seem to have reported and may reflect the multiprofessional nature of many of the postgraduate programmes provided. Respondents were also able to provide specific examples of a direct positive impact on clinical practice; these related to quality improvement measures such as the implementation of evidence-based care pathways and clinical protocols or policies, written as part of the recommendations arising from their Master's dissertations. This evidence fills the previous gap in identifying direct impact on clinical practice.

Limitations of the study

It is acknowledged that the findings are based on an unvalidated survey tool on a sample of self-selected respondents which limits the generalisability of the findings. The majority of respondents were from programmes that had a face-to-face element, so the results may not be applicable to programmes which purely use e-learning or distance learning. Furthermore, the use of a survey to undertake content analysis is a weaker method, but the themes identified could be used in a subsequent follow-up study with a qualitative approach to examine these in more depth. The response rate was low, but because of the anonymous nature of the survey it was not possible to follow up non-respondents.

\section{Conclusions}

This project sought to examine the impact of postgraduate study on healthcare professionals' academic practice and explore potential links to related improvements in clinical practice. The findings suggest that postgraduate programmes of study do have a positive impact on an individual's academic skills which is similar to existing evidence. However, many respondents described an improved ability to understand research and evaluate evidence which is an increasingly important aspect of healthcare. This finding confirms the importance of including this aspect within a postgraduate curriculum. In terms of clinical impact, one of the main themes to emerge was that of an improved sense of multidisciplinary team working which in turn appeared to increase levels of confidence. This was more apparent for programmes which had a face-to-face element but it does highlight the importance of facilitating multidisciplinary activities within a programme of study. The findings also show that graduates are implementing quality improvement strategies through their dissertation projects, for example increased use of clinical audit, introduction of clinical pathways and protocols, to enrich clinical practice. This finding emphasises the significance of providing students with opportunities to undertake clinically relevant projects that are more likely to be integrated into practice.

\section{Acknowledgements}

The authors would like to thank all of the programme directors who assisted with the survey. 


\section{Conflicts of interest}

The authors declare no conflicts of interest.

\section{References}

de Cossart L, Fish D, Thomé R. Education for clinical teachers; does it make a difference? A year in an acute healthcare trust. In: Excellence in Medical Education. Edinburgh: AoME; 2012;3:38-46

Gruppen LD, Frohna AZ, Anderson RM et al. Faculty development for educational leadership and scholarship. Acad Med. 2003;78(2):137-141. https://doi.org/10.1097/00001888-200302000-00007

Hardwick S, Jordan S. The impact of part-time post-registration degrees on practice. J Adv Nurs. 2002;38(5):524-535. https://doi.org/10.1046/j.1365-2648.2002.02214.x

Higher Education Statistics Agency NewDLHE: destinations and outcomes review. 2017. https://www.hesa.ac.uk/innovation/records/reviews/newdlhe (accessed 28 May 2020)

Spencer RL. Nurses', midwives' and health visitors' perceptions of the impact of higher education on professional practice. Nurse Educ Today. 2006;26(1):45-53.

https://doi.org/10.1016/j.nedt.2005.06.006

Steinert Y. Faculty development in the new millennium: key challenges and future directions. Med Teach. 2000;22(1):44-50. https://doi.org/10.1080/01421590078814

Whyte DA, Lugton J, Fawcett TN. Fit for purpose: the relevance of Masters preparation for the professional practice of nursing. A 10-year follow-up study of postgraduate nursing courses in the University of Edinburgh. J Adv Nurs. 2000;31(5):1072-1080. https://doi.org/10.1046/j.13652648.2000.01388.x 